pine oxidoreductase. The deficiencies were confirmed in skin fibroblasts from two siblings with the disease and a third patient from an unrelated family.

\section{REFERENCES AND NOTES}

1. Ampola, M. G., Ampola, M., Mian, M., Shaw, W., Levy, H., Letsou, A., and Doyle, M.: In preparation.

2. Bowden, J. A., and Connelly, J. L.: Branched-chain $\alpha$-keto acid metabolism. I Isolation, purification and partial characterization of bovine liver $\alpha$ ketoisocaproic: $\alpha$-keto- $\beta$-methylvaleric acid dehydrogenase. J. Biol. Chem. 243: 1198 (1968).

3. Cox, R. P., Krauss, M. R., Balis, M. E., and Dancis, J.: Communication between normal and enzyme deficient cells in tissue culture. Exp. Cell Res., 74: 251 (1972).

4. Cox, R. P., and MacLeod, C. M.: Alkaline phosphatase content and the effects of prednisolone on mammalian cell cultures. J. Gen. Physiol., 45: 439 (1962).

5. Dancis, J.: Abnormalities in the degradation of lysine. In: W. L. Nyhan: Heritable Disorders of Amino Acid Metabolism, Ed. 1, p. 387 (John Wiley and Sons, New York, 1974).

6. Dancis, J., Hutzler, J., Cox, R. P., and Woody, N. C.: Familial hyperlysinemia with lysine-ketoglutarate reductase insufficiency. J. Clin. Invest., 48: 1447 (1969)

7. Dancis, J., Yip, L. C., Cox, R. P., Piomelli, S., and Balis, M. E.: Disparate enzyme activity in erythrocytes and leucocytes: A variant of hypoxanthine phosphoribosyltransferase deficiency with an unstable enzyme. J. Clin. Invest. 52: 2068 (1973).

8. Fellows, F. C. I.: Biosynthesis and degradation of saccharopine, an intermediate of lysine metabolism. Biochem. J., 136: 321 (1973).

9. Fellows, F. C. I., and Carson, N. A. J.: Enzyme studies in a patient with saccharopinuria: A defect of lysine metabolism. Pediat. Res, 8:42 (1974).

10. Fjellstedt, T. A., and Robinson, J. C.: Purification and properties of L-lysine- $\alpha-$ ketoglutarate reductase from human placenta. Arch. Biochem. Biophys., 168 536 (1975).

11. Fisher, M. H., Gerritsen, T., and Opitz, J. M.: $\alpha$-Amino aciduria, a non-deleterious inborn metabolic defect. Humangenetik, 24: 265 (1974).

12. Gatfield, P. D., Taller, E., Hinton, G. G., Wallace, A. C., Abdelnour, G. M., and Haust, M. D.: Hyperpipecolatemia: A new metabolic disorder associated with neuropathy and hepatomegaly. A case study. Can. Med. Ass. J., 99: 1215 (1968)

13. Gelderen, H. H., and Teijema, H. L.: Hyperlysinemia: Harmless error of metabolism? Amer. J. Dis. Child., 48: 892 (1973).

14. Goodman, S. I., Markey, S. P., Moe, P. G., Miles, B. S., and Teng, C. C.:
Glutaric aciduria: A "new" disorder of amino acid metabolism. Biochem. Med., 12: 12 (1975)

15. Hutzler, J., and Dancis, J.: Saccharopine cleavage by a dehydrogenase of human liver. Biochim. Biophys. Acta, 206: 205 (1970).

16. Hutzler, J., and Dancis, J.: Preparative synthesis of saccharopine. Biochim Biophys. Acta, 222: 225 (1970)

17. Hutzler, J., and Dancis, J.: Lysine-ketoglutarate reductase in human tissues Biochim. Biophys. Acta, 377: 42 (1975).

18. Krooth, R. S.: Constitutive mutations and hereditary enzyme deficiencies in mammalian cells. In: M. Harris and B. Thompson: Regulation of Gene Expression in Eukaryotic Cells, p. 115 (Fogarty International Center, Bethesda, Md., 1973).

19. Lormans, S., and Lowenthal, A.: Amino adipic aciduria in an oligophrenic child Clin. Chim. Acta, 57: 97 (1974).

20. Lowry, O. H., Rosebrough, N. J., Farr, A. L., and Randall, R. J.: Protein measurement with the Folin phenol reagent. J. Biol. Chem. 193: 265 (1951).

21. Nakatani, Y., Fujioka, M., and Higashino, K.: $\alpha$-Aminoadipate aminotransferase of rat liver mitochondria. Biochim. Biophys. Acta, 198: 219 (1970).

22. Przyrembel, H., Bachmann, D., Lombeck, I., Becker, K., Wendel, U., Wadman, S. K., and Bremer, H. J.: Alpha-ketoadipic aciduria, a new inborn error of lysine metabolism; biochemical studies. Clin. Chim. Acta, 58: 257 (1975).

23. Smith, L. H., Jr., Huguley, C. M., Jr., and Bain, J. A.: Hereditary orotic aciduria. In: J. B. Stanbury, J. B. Wyngaarden, and D. S. Fredrickson: The Metabolic Basis of Inherited Diseases, Ed. 3, p. 1003 (McGraw Hill Book Co, New York, 1972).

24. Wendel, U., Rudiger, H. W., Przyrembel, H., and Bremer, H. J.: Alphaketoadipic aciduria: Degradation studies with fibroblasts. Clin. Chim. Acta, 58: 271 (1975)

25. Wilson, R. W., Wilson, C. M., Gates, S. C., and Higgins, J. V.: $\alpha$-ketoadipic aciduria: A description of a new metabolic error in lysine-tryptophan degradation. Pediat. Res., 9: 522 (1975).

26. Woody, N. C.: Hyperlysinemia. Amer. J. Dis. Child., 108: 543 (1964)

27. Woody, N. C., Hutzler, J., and Dancis, J.: Further studies of hyperlysinemia Amer. J. Dis. Child., 112: 577 (1966).

28. Informed consent for skin biopsy was obtained on all patients. The protocols for this procedure were reviewed and approved by the Committee for Protection of Human Subjects.

29. This study was supported by National Institutes of Health Grants HDO 4526 , AM 14528, and HDO 2920.

30. Requests for reprints should be addressed to: J. Dancis, M.D., Department of Pediatrics, New York University Medical Center, 550 First Ave., New York, N. Y. 10016 (USA).

31. Accepted for publication February 13, 1976.
Jejunal mucosa phosphate rickets, hypophosphatemic small intestine transport

\title{
Intestinal Phosphate Transport in Familial Hypophosphatemic Rickets
}

\author{
FRANCIS H. GLORIEUX, ${ }^{(36)}$ CLAUDE L. MORIN, ROSE TRAVERS, EDGARD E. DELVIN, AND \\ ROGER POIRIER
}

The Genetics Unit, Montreal Shriners Hospital; The Department of Paediatrics, University of Montreal; and The Departments of Paediatrics and Surgery, McGill University, Montreal, Quebec, Canada

\section{Extract}

The present report outlines an attempt to characterize inorganic phosphate uptake by human jejunal mucosa using biopsy material obtained from six patients affected by the X-linked form of vitamin D-resistant rickets and six control subjects.

The tissue from control subjects accumulated ${ }^{32} \mathrm{P}$ actively in a linear fashion against time. The incorporation of inorganic phosphate into organophosphate derivatives is rapid and equilibrates after $\mathbf{1 0} \mathrm{min}$ at an inorganic over total phosphate ratio of $\mathbf{0 . 4 5}$. Concentrative uptake and incorporation were both suppressed by anaerobiosis or cyanide. Rates of phosphate uptake and incorporation into the organic derivatives by the tissue of hypophosphatemic patients are comparable with normal values.

Saturation kinetics observed over a wide range of substrate concentrations $(0.003$ to $3 \mathrm{mM})$ elicits only one transport system with an apparent Michaelis constant of $0.2 \mathrm{mM}$ and a maximum velocity of $0.7 \mathrm{mmol} /$ liter $/ 40 \mathrm{~min}$. The kinetic data obtained from the patients do not strikingly differ from the control values. The chemical analysis of the phosphate content of intestinal mucosa from two patients and two control subjects indicates that the tissue is not specifically phosphate-depleted in the mutant individuals. 
These results are in accordance with the positive results obtained with the oral replacement therapy in familial hypophosphatemia.

\section{Speculation}

The mutation causing X-linked hypophosphatemic rickets affects the capacity of epithelial cells to transport inorganic phosphate. Although this has been clearly demonstrated in the kidney, the involvement of intestinal cells is a matter of debate. The present report does not answer that question definitely but suggests that a primary intestinal transport abnormality is not part of the basic defect underlying the familial hypophosphatemic rickets (XLH) phenotype. Other approaches using human tissues or animal models may allow a more precise evaluation of the cellular events regulating the transepithelial transfer of phosphate.

Familial hypophosphatemic rickets, one of the several forms of vitamin D-resistant rickets, is a condition in which the conservation of phosphate is severely impaired. The mutation is transmitted as an X-linked dominant trait and its hallmarks are a low plasma inorganic phosphorus $\left(\mathrm{P}_{\mathrm{i}}\right)$ bone changes as observed in vitamin D deficiency, and severe growth failure. Since its first clinical description by Albright in 1937 (1), the theories to account for the phenotypic expression of this mutation have evolved along two main lines. The first favored a primary defect in vitamin D metabolism, which would cause impaired calcium absorption by the gut, and secondary hyperparathyroidism (4). The latter, through its well known hyperphosphaturic effect, would generate chronic hypophosphatemia. This theory has lost most of its support by the demonstration that serum levels of immunoreactive parathyroid hormone in this condition are normal $(2,11)$ or slightly elevated, but well below the range of proved hyperparathyroidism (25). In addition, neither vitamin D itself nor any of its presently isolated metabolites are able to correct the hypophosphatemia in a sustained fashion $(5,16)$. Therefore, attention was focused on the alternate theory that the mutation affects primarily the reclamation of phosphate by the renal tubular cells. In favor of this view is the recent demonstration that a parathyroid hormone (PTH)-sensitive component of phosphate transport is defective in the kidneys of mutant individuals (13). The phenotype is fully expressed in the male and variably so in the female patients, as is expected in the case of an X-linked dominant trait.

Whether other cells and organs are also affected by the mutation, as in other inborn errors of transport (26), has been the subject of several studies. The erythrocyte membrane does not seem to transport inorganic phosphate actively (6). Even though some facilitated diffusion does occur, no difference could be elicited between cells from normal and mutant individuals (29). Jejunal mucosa also attracted attention because of its functional similarity to the renal tubular cells and the reported increased amounts of phosphate in stools of XLH patients $(9,27)$. Condon et al. (8) have suggested a defect of phosphate intestinal absorption in familial and nonfamilial hypophosphatemia. Their argument is based on an elevation of plasma $P_{i}$, lower in the patients than in the normal individuals, after a single oral dose of $1.5 \mathrm{~g}$ phosphorus. However, their protocol cannot eliminate the possibility that inorganic phosphate is distributed more rapidly in the various phosphate pools in the chronically depleted organisms. Moreover, their hypothesis is not supported by two clinical observations. The first, by Gunther et al. (19), established that in one case of $\mathrm{XLH}$, oral radioactive phosphorus was practically completely absorbed unless given with food. The second, reported by Gerbeaux-Balsan (12), indicates that in XLH patients under various dietary conditions a primary defect in intestinal phosphorus absorption is not part of the XLH phenotype.

The in vitro study of $\mathrm{P}_{\mathrm{i}}$ absorption by intestinal mucosa has been extensively studied in the rat and in the chick. In the mammal, with an everted gut sac model, Harrison and Harrison (21) established that phosphate transport occurred against the electrochemical gradient requiring energy; that it needed calcium to be present in the bathing solution; and that it was enhanced by prior treatment of the animal with vitamin D. The latter effect was thought to be indirect by vitamin D, making calcium available to the appropriate site of the phosphate transport system. However, Kowarski and Schachter (24) suggested that vitamin D affected phosphate transport directly since it influenced it more effectively in the jejunum, whereas its effect on calcium transport takes place mainly in the duodenum. Recently, Chen et al. (7) reported that phosphate transport by rat jejunal mucosa was enhanced by 1 $\alpha, 25$-dihydroxycholecalciferol, the kidney-produced active form of vitamin D, but was not influenced by the calcium concentration in the medium.

In the intact chick, Hurwitz and Bar (23) observed the same segmental selectivity for calcium and phosphate absorption reported in the rat (24), favoring the fact that phosphate uptake is independent of the movements of the calcium ion. Wasserman and Taylor (31), by the in situ ligated loop technique in the chick, reached the same conclusions and presented the view that $P_{i}$ uptake from the gut lumen is a saturable function and that release of $P_{i}$ from tissue to blood is a rate-limiting step.

The first report on $\mathrm{P}_{\mathrm{i}}$ uptake in vitro by hum tissue was made by Short et al. (27) using biopsy specimens of jejunal mucosa. They concluded that under their experimental conditions phosphate uptake was mediated by at least two systems, and suggested that one of them could be inactivated by the XLH mutation. The present report outlines our own attempt to characterize $P_{i}$ uptake by human jejunal mucosa obtained from XLH mutants and control subjects using a similar in vitro system.

\section{MATERIALS AND METHODS}

\section{SUBJECTS}

Five children (two male, three female) and one adult female were selected for the study. They all exhibited a history of ricketic bone alterations and severe growth failure. None of the patients had active rickets at the time of the study. Renal tubular reabsorption of phosphate was depressed. Their biochemical phenotypes are summarized in Table 1. Levels of immunoreactive parathyroid hormone (iPTH) were within the normal range for the antiserum used (except for patient 5). They all had a poor or negative phosphaturic response to intravenous purified bovine PTH (32). Patient 5 refused the test. Five of the subjects had received large doses of vitamin D which was stopped 5 weeks before the study. However, their pool of circulating 25-hydroxycholecalciferol was still significantly enlarged. None had received oral phosphate supplementation before the study except patient 5 , who had been given erratic phosphate supplementation with poor follow-up. As expected, he developed severe secondary hyperparathyroidism with bone changes. Phosphate intake had been stopped 2 months before the biopsy.

Six adult normal volunteers constituted the control group. For ethical reasons no subject under 16 years of age could be included in this group. Informed consent before the procedures was obtained from all subjects or their parents.

\section{ANALYTIC METHODS}

Serum calcium and phosphorus were determined by Technicon AutoAnalyzer methods. Tubular reabsorption of phosphorus based on the creatinine clearance was measured in the morning on a 3-hr urine collection. Circulating iPTH was evaluated by radioimmunoassay by Dr. Claude Arnaud and in this laboratory using antisera (GP $1 \mathrm{M}$ and $\mathrm{CH} 12 \mathrm{M}$ ) directed against the carboxy-terminal end of the PTH molecule. This type of antiserum is thought to be the most appropriate to diagnose a status of hyperparathyroidism (3). Circulating 25-hydroxycholecalciferol (25-HCC) was measured by a modification of the radioligand assay published by Haddad and Chyu (20). 
Table 1. Biochemical phenotype of selected patients

\begin{tabular}{|c|c|c|c|c|c|c|c|c|}
\hline \multirow[b]{2}{*}{ Patients $^{1}$} & \multirow[b]{2}{*}{ Age } & \multirow[b]{2}{*}{ Sex } & \multicolumn{4}{|c|}{ Serum } & \multirow[b]{2}{*}{$\begin{array}{c}\text { TRP, }{ }^{5} \\
\%\end{array}$} & \multirow[b]{2}{*}{$\begin{array}{l}\text { PTH }^{6} \\
\text { infusion }\end{array}$} \\
\hline & & & $\begin{array}{l}\text { Calcium, } \\
\mathrm{mg} / \mathrm{dl}\end{array}$ & $\begin{array}{c}\mathrm{P}_{\mathrm{i}}{ }^{2} \\
\mathrm{mg} / \mathrm{dl}\end{array}$ & $\begin{array}{l}\text { iPTH, }{ }^{3} \\
\mathrm{ng} / \mathrm{ml}\end{array}$ & $\begin{array}{c}25-\mathrm{HCC}{ }^{4} \\
\mathrm{ng} / \mathrm{ml}\end{array}$ & & \\
\hline 1 & 9 & $\mathrm{~F}$ & 10.1 & 2.3 & 20 & 509 & 47 & 1.2 \\
\hline 2 & 15 & $\mathrm{~F}$ & 10.2 & 2.3 & 10 & 556 & 48 & 1.0 \\
\hline 3 & 10 & $\mathrm{~F}$ & 9.8 & 3.1 & 18 & 575 & 82 & 1.0 \\
\hline 4 & 12 & M & 10.3 & 1.4 & 58 & 296 & 20 & 1.2 \\
\hline 5 & 17 & $\mathrm{M}$ & 10.0 & 1.8 & 262 & 507 & 86 & - \\
\hline 6 & 46 & $\mathrm{~F}$ & 9.0 & 1.5 & 54 & 19.2 & 64 & 1.2 \\
\hline
\end{tabular}

${ }^{1}$ Patients 1,2 , and 3 are siblings.

${ }^{2} \mathrm{P}_{\mathrm{i}}$ : inorganic phosphate. All values below 2.5 SD for age and sex according to the data of Greenberg et al. (18).

${ }^{3}$ iPTH: immunoreactive parathyroid hormone. Radioimmunoassay with GP $1 \mathrm{M}$ and $\mathrm{CH} 12 \mathrm{M}$ antisera, normal range $<50 \mathrm{ng} / \mathrm{ml}$.

${ }^{4}$ 25-HCC: 25-hydroxycholecalciferol. Normal values $30 \pm 9 \mathrm{ng} / \mathrm{ml}$ (mean $\pm 1 \mathrm{SD}$ ).

${ }^{5}$ TRP: tubular reabsorption of phosphate.

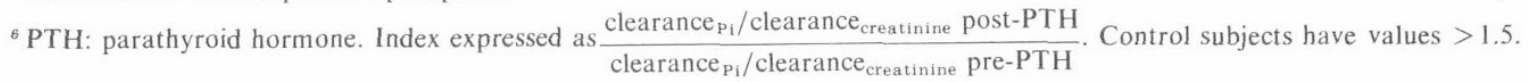

The response to intravenous bovine PTH was assessed as previously described (13).

\section{IN VITRO STUDIES}

Peroral samples of jejunal mucosa were obtained with a capsule of Carey placed distal to the ligament of Treitz under fluoroscopic control. Samples, averaging $20 \mathrm{mg}$ in weight, were rapidly cut into fragments of $1-2 \mathrm{mg}$ and kept at $4^{\circ}$ in a phosphate-free medium (Tris, $27.5 \mathrm{mM} ; \mathrm{CaCl}_{2} \cdot 2 \mathrm{H}_{2} \mathrm{O}, 1.37 \mathrm{mM} ; \mathrm{MgSO}_{4} \cdot 7 \mathrm{H}_{2} \mathrm{O}, 1.25$ $\mathrm{mM}$; $\mathrm{KCl}, 5 \mathrm{mM}$; $\mathrm{NaCl}, 125 \mathrm{mM}$; pH 7.4) for $10-30 \mathrm{~min}$. The medium was constantly gased with oxygen. Specimens were then incubated in individual flasks containing fresh medium and $0.003-3 \mathrm{mM}$ inorganic phosphate as $\mathrm{NaH}_{2} \mathrm{PO}_{4}$. The marker was $\left[{ }^{32} \mathrm{P}\right] \mathrm{NaH}_{2} \mathrm{PO}_{4}$ at a concentration of $0.003 \mathrm{mM}$. Total incubation volume was $2 \mathrm{ml} /$ flask. A constant flow of oxygen was passed through the gas phase of each flask. After 10-40 min of incubation at $37^{\circ}$ in a shaking water bath, the tissue was removed, rinsed in cold saline, gently blotted, and homogenized in $1 \mathrm{ml} 10 \%$ trichloroacetic acid (TCA), at $4^{\circ}$. After centrifugation at 200,000 $\times \mathrm{g} \cdot \mathrm{min}$ in the cold, the supernatant was divided in two fractions: $0.2 \mathrm{ml}$ was dissolved in $1 \mathrm{ml} \mathrm{NCS}$ and $9 \mathrm{ml}$ Omnifluor for counting of the total ${ }^{32} \mathrm{P}$ content of the tissue; $0.5 \mathrm{ml}$ was treated for extraction of the ${ }^{32} \mathrm{P}_{1}$ present in the sample. To accurately measure the proportion of absorbed $\mathrm{P}_{1}$ that had been incorporated in the organic phosphate derivatives during incubation, a method was selected that does not hydrolyze the labile phosphoric esters present in the tissue. In separate experiments labeled adenosine triphosphate $\left(\left[\gamma-{ }^{32} \mathrm{P}\right] \mathrm{ATP}\right)$ was diluted in phosphate-free incubation medium, kept for $40 \mathrm{~min}$ at $37^{\circ}$, and then treated according to the method of Vestergaard-Bogind (30) for separation of acid-soluble organic and inorganic phosphorus. Only $0.8 \%$ of the total radioactivity was recovered in the inorganic phase, contrasting with the Lippman and Tuttle method, as modified by Short et al. (27), in which $83.7 \%$ of the tracer was present in the inorganic phase. The latter being therefore inadequate for measuring the incorporation of inorganic phosphorus, the former technique was used throughout the present study. The amount of radioactivity present in the incubation medium was assessed separately for each flask. All countings were performed in a Packard 3385 liquid scintillation spectrometer equipped with an automatic external standardization system. The tissue water space was determined by incubation of a tissue sample for $40 \mathrm{~min}$ in a medium containing $\left[{ }^{14} \mathrm{C}\right]$ inulin as previously described (14). The isotope distribution ratio for total ${ }^{32} \mathrm{P}$ and inorganic ${ }^{32} \mathrm{P}$ was calculated as the ratio of radioactivity per $\mathrm{ml}$ cell water to radioactivity per $\mathrm{ml}$ incubation medium.

As the chemical measurement of acid-soluble total and inor- ganic phosphate content of the tissue required a minimum of $10 \mathrm{mg}$ material, four separate biopsies (two controls, 2 hypophosphatemic rickets) were performed for that purpose. The tissue was homogenized in 10\% TCA as above and the supernatant separated into two fractions. For the first, $0.5 \mathrm{ml}$ was added to a mixture of silicotungstate-molybdate and isobutanol-benzene and extracted by vigorous shaking (30). The upper phase was then mixed with ethanol-sulfuric acid, $2 \%$, and stannous chloride-sulfuric acid, $0.4 \%$. After storage in the dark for at least $15 \mathrm{~min}$, the optical density was read on a spectrophotometer (Varian, model 365) at $725 \mathrm{~nm}$ against distilled water for estimation of the inorganic phosphate concentration. The second fraction, $0.4 \mathrm{ml}$, was hydrolyzed at $80^{\circ}$ for $4 \mathrm{hr}$ and then treated as the first fraction for estimation of the total phosphate concentration.

\section{RESULTS}

When the time course of radioactive phosphate uptake by jejunal mucosa was measured, the tissue from control subjects accumulated the substrate actively in a linear fashion against time, reaching a maximal distribution ratio of $4.2 \pm 0.9$ (mean \pm 1 SD). Equilibrium was not achieved after $40 \mathrm{~min}$ (Fig. 1). The incubation was not carried beyond that limit since it was noticed that after 60 min tissue damage caused a sharp decrease in its transport ability. The incorporation of the label in the acid-soluble organic phosphate pool was rapid and equilibrated after $10 \mathrm{~min}$ at an inorganic over total phosphate ratio $\left(\mathrm{P}_{\mathrm{i}} / \mathrm{P}_{\mathrm{t}}\right)$ of 0.45 . That ratio was maintained during the whole incubation. Concentrative uptake (distribution ratio higher than 1) and incorporation into the organic pool were both suppressed by incubating the tissue under nitrogen or in the presence of cyanide.

As already denoted by Short et al. (27), we observed that phosphate uptake in jejunal mucosa biopsy specimens was inversely proportional to tissue weight. The reason for this is probably that a larger sample comprises more tissue inactive in terms of transport, leading to an artifactual lowering of the distribution ratio. Therefore, only specimens weighing between 1 and $2 \mathrm{mg}$ were used in subsequent studies.

The time course of ${ }^{32} \mathrm{P}$ uptake by the tissue of hypophosphatemic patients was measured in two individuals (patients 5 and 6) (Fig. 2). That tissue accumulated the substrate actively to reach an isotope distribution ratio of $5.0 \pm 0.5$ after $40 \mathrm{~min}$ of incubation. The incorporation of $\mathrm{P}_{i}$ into the organic derivatives was also comparable with normal values $\left(P_{i} / P_{1}\right.$ ratio: $0.45 \pm 0.09$ in controls; $0.46 \pm 0.05$ in XLH patients after $40 \mathrm{~min}$ of incubation).

When phosphate uptake was examined over a wide range of substrate concentrations, saturation kinetics were observed. The 


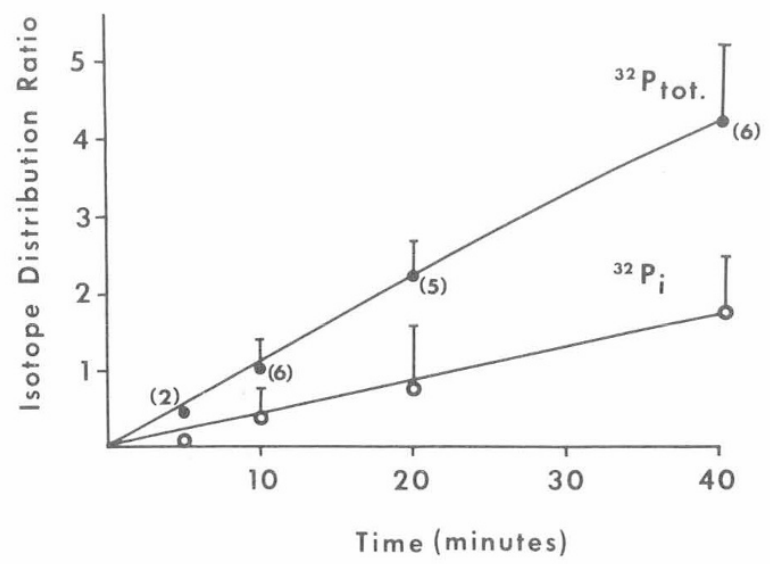

Fig. 1. Time course of uptake of radioactive total $\left({ }^{32} P_{t o t}\right)$ and inorganic phosphate $\left({ }^{32} P_{i}\right)$ by jejunal mucosa from six control subjects. Biopsies were incubated with $0.003 \mathrm{mM}^{32} \mathrm{P}_{\mathrm{i}}$ in Tris buffer $\left(\mathrm{pH} \mathrm{7.4)}\right.$ ) at $37^{\circ}$. Means \pm 1 $\mathrm{SD}$ are shown. The number of determinations is in parentheses.

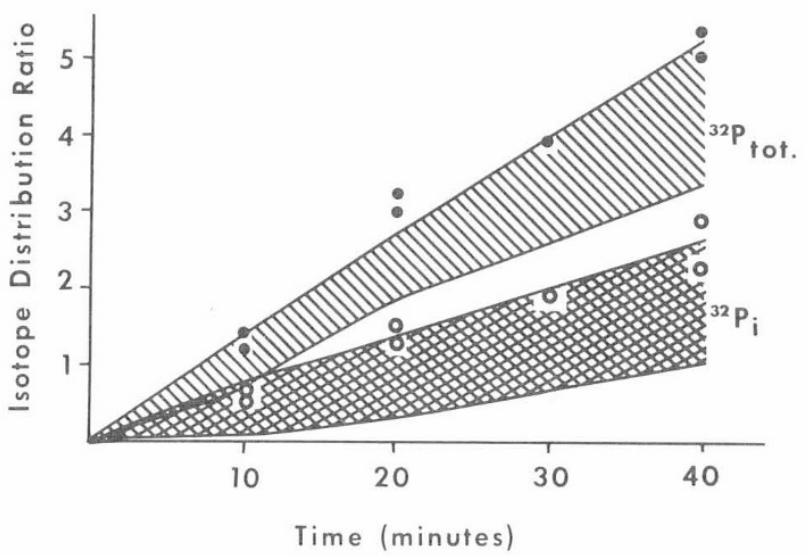

Fig. 2. Time course of the total $(-)$ and inorganic $(O)$ phosphate uptake by jejunal mucosa samples from two hypophosphatemic patients (one male, one female). The hatched areas represent the "normal range" covered by the means $\pm 1 \mathrm{SD}$ of the values obtained from the control samples incubated in identical conditions, as depicted in Figure 1.

data plotted according to Lineweaver and Burk (1/u vs. 1/S) fell along a single straight line with a correlation coefficient of 0.98 (Fig. 3). We have not been able to elicit the two transport systems with widely different affinity reported by Short et al. (27). The regression lines calculated from our data artificially separated in two groups on either side of the reported break generated lines with similar slopes not different from the one calculated for the whole group. The apparent Michaelis constant $\left(\mathrm{K}_{\mathrm{m}}\right)$ of the system was $0.2 \mathrm{mM}$ and its maximum velocity was $0.7 \mathrm{mmol} /$ liter $/ 40 \mathrm{~min}$.

The kinetic data obtained in our six patients do not strikingly differ from those observed in control subjects (Fig. 4). At very low substrate concentration $(0.003 \mathrm{mM})$ the XLH group even exhibited a rate of uptake significantly higher $(p<0.05)$ than control subjects.

The chemical analysis of total and inorganic phosphate content of mucosa samples obtained separately from the transport studies are shown in Table 2. There are not enough data for conclusive results, but there is indication that the $\mathrm{XLH}$ jejunal mucosa is not specifically phosphate depleted and that the proportion of the TCA-soluble phosphate present in the inorganic form is similar, about $50 \%$, to the isotopic distribution observed during the transport experiments.

\section{DISCUSSION}

The present data confirm that the uptake of phosphate by human intestinal mucosa is an energy-dependent, concentrative process. Since anaerobic conditions or incubation with cyanide also abolish the incorporation of the tracer into the organic phosphate derivatives, it is suggested that this step is critical for the transfer process. Whether it is also energy dependent cannot be concluded from our data, because the nonincorporation into the organic pool under the above mentioned conditions may only indicate that organification depends on the size of the pool of the accumulated $P_{1}$.

It is clear that any in vitro model of a biologic function has its limitations and that extrapolation of its results to what is actually taking place in vivo is hazardous. Such a problem had been raised concerning the use of kidney cortex slices to study the process of tubular reabsorption. Foulkes (10) demonstrated that, in slices, mostly basal membranes of epithelial cells were exposed to the surrounding medium and, therefore, the properties of the luminal cell membranes were not explored. Preliminary data on renal phosphate handling both in vivo and in vitro in a strain of hypophosphatemic mice confirm this view (15). A similar situation may exist with the model used by Short et al. (27) and in the

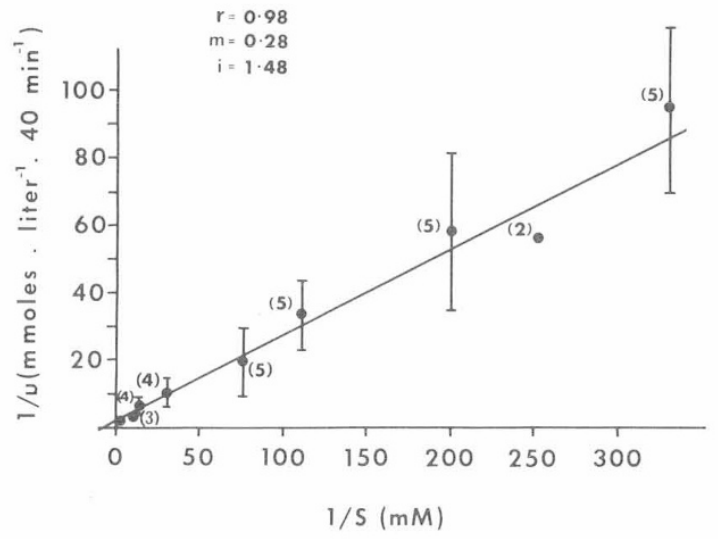

Fig. 3. Double reciprocal plot of total ${ }^{32} \mathrm{P}$ transport by jejunal mucosa from control subjects. Biopsy specimens were incubated for $40 \mathrm{~min}$ with substrate concentrations $(S)$ from $0.003-3 \mathrm{mM}$. To take into account the diffusion constant (14), the mediated velocity $(u)$ was calculated by subtracting 1 from the observed distribution ratios for ${ }^{32} \mathrm{P}$ at each of the nine substrate concentrations studied. Means \pm 1 SD are shown. The number of determinations is in parentheses. The regression line calculated from the data is monophasic with a correlation coefficient of 0.98 . From this line, the Michaelis constant is estimated to be $0.2 \mathrm{mM}$ and the maximum velocity $0.7 \mathrm{mmol} / \mathrm{liter} / 40 \mathrm{~min}$.

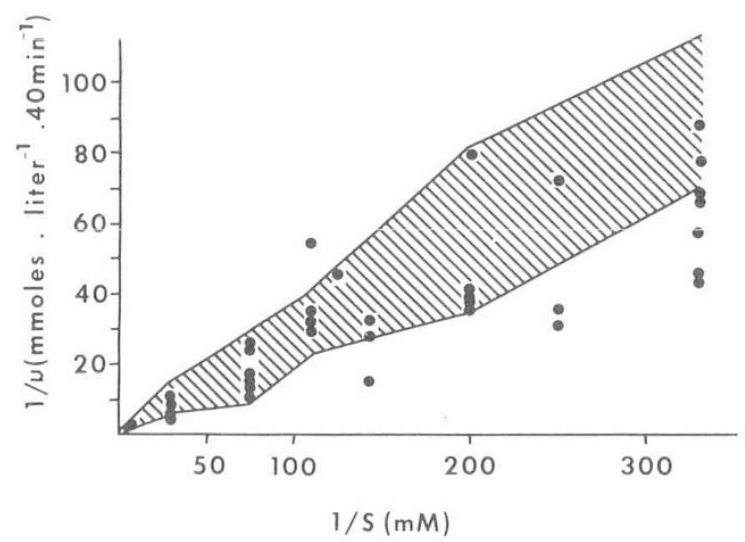

Fig. 4. Lineweaver-Burk transformation of the kinetic data obtained from hypophosphatemic mucosa samples after $40 \mathrm{~min}$ of incubation. The hatched area represents the "normal range" as defined by the mean \pm I SD of control values (Fig. 3). Each symbol (-) represents the mean result of a duplicate analysis for one patient at a given substrate concentration. At substrate concentration $(S)$ of $0.003 \mathrm{mM}(1 / \mathrm{S}=333)$, the data from hypophosphatemic patients significantly differ from the control data $(p<$ 0.05 , determined by Student's $t$-test). 
Table 2. Tissue and serum phosphate concentrations in normal and hypophosphatemic $(X L H)$ subjects $^{1}$

\begin{tabular}{lcccc}
\hline & \multicolumn{3}{c}{ Tissue, $\mu \mathrm{g} / \mathrm{g}$ wet wt } & \\
\cline { 2 - 4 } Subjects & $\mathrm{P}_{\mathrm{i}}{ }^{3}$ & $\mathrm{P}_{\mathrm{t}}{ }^{3}$ & $\mathrm{P}_{\mathrm{i}} / \mathrm{P}_{\mathrm{t}}$ & $\mathrm{P}_{\mathrm{i}}, \mathrm{mg} / \mathrm{dl}$ \\
\hline Control & & & & \\
$\quad 1$ & 235 & 4 & & 4.1 \\
2 & 159 & 363 & 0.44 & 3.1 \\
XLH & 135 & 4 & & \\
1 & 193 & 403 & 0.48 & 2.2 \\
2 & & & & 2.1 \\
\hline
\end{tabular}

${ }^{1}$ All values are means of triplicate analysis. $\mathrm{P}_{\mathrm{i}}$ : inorganic phosphate; $\mathrm{P}_{\mathrm{t}}$ : totai phosphate.

${ }^{2}$ At the time of the biopsy.

${ }^{3}$ Inorganic and total phosphate content of the TCA-soluble tissue extract.

${ }^{4} \mathrm{P}_{\mathrm{t}}$ content unavailable.

present study. In vivo transepithelial transfer of inorganic phosphate involves uptake from the gut lumen, incorporation of the solute into labile phosphoesters, and release to blood (31). We cannot ascertain which step is predominant in our model but we have at least demonstrated that it is energy dependent and involves the incorporation of $\mathrm{P}_{4}$ into the organic pool. Furthermore, it is not influenced by vitamin $D$, since there was no difference between the vitamin D-treated (patients $1-5$ ) and the not treated (patient 6 and all the control subjects) groups. This last point is of interest because Wasserman and Taylor (31) have shown that the transfer from tissue to blood is the most sensitive step for vitamin D. It is therefore possible that in our model this latter step is not particularly active and that we are looking mainly at the properties of the luminal cell membranes. Moreover, by analogy with the renal defect that can be evidenced in vitamin D-treated patients (13), it is unlikely that prior vitamin D therapy would conceal an intestinal abnormality.

Taking into account these limitations, the main purpose of the present study was to try to further document the relative defect reported by Short et al. (27) in at least one XLH hemizygous patient. We found our data at variance with their report, not only with regard to the characteristics of intestinal ${ }^{32} \mathrm{P}$ uptake in patients, but also to uptake in control subjects.

In the normal tissue, Short et al. (27) obtained, after a 40-min incubation, an isotope distribution ratio higher than the one we achieved. Because of the wide standard deviation of their four determinations, the difference is probably unimportant. Comparisons should also take into account that these authors only consider the inorganic phosphate uptake. However, since the extraction procedure they used hydrolyses the terminal phosphate group of ATP (see Materials and Methods), their $\mathrm{P}_{\text {is }}$ distribution ratio corresponds mostly to the total TCA-soluble phosphate taken up by the tissue and should be compared with our total phosphate distribution ratio. It is justified to use the latter as an index of uptake, as our data show that the incorporation into the organophosphate derivatives is closely linked to the energy-dependent process. That the isotopic $\mathrm{P}_{1} / \mathrm{P}_{1}$ ratio has some physiologic meaning is suggested by its similarity with the actual chemical $\mathrm{P}_{\mathrm{i}} / \mathrm{P}_{1}$ ratio measured separately in one control and one $\mathrm{XLH}$ patient (Table 2).

One major discrepancy between the study of Short et al. (27) and the present study lies in the evaluation of the kinetics of phosphate uptake by jejunal mucosa from control subjects. We have not been able to reproduce the biphasic curve on which is based the proposal that phosphate uptake is mediated by two systems with widely different affinities. We could only elicit one transport system from our data obtained at nine different substrate concentrations. The Michaelis constant and the maximum velocity of this system are not strikingly different from those published by Short et al. (27) for their "low-affinity system." No trace of a "high-affinity system" was found. The possible role played by the difference in the buffers used in the incubation medium (bicarbonate in the study of Short et al. and Tris in the present study) has been ruled out by preliminary experiments in which we observed no difference in uptake by incubating in either solution. Moreover, the analogy made by Short et al. (27) with the data previously obtained in the XLH kidney in vivo (13) has to take into account the limitations discussed earlier.

The kinetic analyses performed in the XLH patients also disagree with the suggestion that a "high affinity" transport system is lost in the mutant individuals (27). At very low substrate concentrations $(\mathrm{S}=0.003 \mathrm{mM})$ the rate of uptake is even higher in the XLH group, the difference being statistically significant $(p<$ 0.05 ). The fact that this may represent an adaptative process of phosphate-depleted organisms cannot be ruled out. Although genetic heterogeneity, so often reported in inherited metabolic disorders, may be invoked for explaining the differences between Short's (27) and the present report, the fact that data obtained from control specimens are also at variance makes it difficult to infer that it is the sole basis for explaining the discrepancy.

It should also be pointed out that if the absence of a significant defect for phosphate transport in the XLH jejunal mucosa agrees with some clinical reports $(12,19)$, it also verifies the positive results obtained with the oral replacement therapy in familial hypophosphatemia (17). The chemical estimations of the jejunal mucosa phosphate content reported in Table 2, although scarce, seem to indicate that the total and inorganic TCA-soluble phosphate pools are probably not significantly decreased in XLH intestinal cells. Whether the mutation affects the rate of exchanges among the various extra- and intracellular phosphate pools in a manner that could not be elicited in the model used in the present study will be the subject of subsequent investigations.

\section{SUMMARY}

X-linked hypophosphatemic rickets is caused by a mutation that affects the reclamation of phosphate by the renal tubular cells. The possibility that a similar defect could be expressed in the jejunum mucosal cells, as recently suggested (27), was investigated using peroral biopsy samples obtained from six hypophosphatemic patients and six control subjects. Specimens, weighing under $2 \mathrm{mg}$, were incubated for 5-40 $\mathrm{min}$ in Tris buffer, $\mathrm{pH} 7.4$, with substrate concentrations from $0.003-3 \mathrm{mM}$. Energy-dependent concentrative uptake was equally active in the two groups. Incorporation of inorganic phosphate into the labile phosphoesters was rapid and equilibrated at an inorganic to total ${ }^{32} \mathrm{P}$ ratio of 0.5 in both groups. Only one mediated transport system for phosphate was present in normal subjects with a Michaelis constant $\simeq 0.2 \mathrm{mM}$ and a maximum velocity $\simeq 0.7 \mathrm{mmol} / \mathrm{liter} / 40 \mathrm{~min}$. Similar kinetic data were obtained in the group of patients. If the X-linked mutation affects the capacity of the intestinal cells to transport phosphate, it does so in a way that cannot be touched upon with the in vitro model used in the present study.

\section{REFERENCES AND NOTES}

1. Albright, F., Butler, A. M., and Bloomberg, E.: Rickets resistant to vitamin D therapy. Amer. J. Dis. Child., 54: 529 (1937).

2. Arnaud, C., Glorieux, F., and Scriver, C.: Serum parathyroid hormone in X-linked hypophosphatemia. Science, 173: 845 (1971).

3. Arnaud, C. D., Goldsmith, R. S., Bordier, P. J., Sizemore, G. W., Larsen, J. A. and Gilkinson, J.: Influence of immunoheterogeneity of circulating parathyroid hormone on results of radioimmunoassay of serum in man. Amer. J. Med., 56: 785 (1974).

4. Avioli, L. V., Williams, T. F., Lund, J., and DeLuca, H. F.: Metabolism of vitamin $\mathrm{D}_{3}-{ }^{3} \mathrm{H}$ in vitamin D-resistant rickets and familial hypophosphatemia. J. Clin. Invest., 46: 1907 (1967).

5. Brickman, A. S., Coburn, J. W., Kurokawa, K., Bethune, J. E., Harrison, H. E, and Norman, A. W.: Actions of 1,25-dihydroxycholecalciferol in patients with hypophosphatemic, vitamin-D rickets. N. Engl. J. Med., 289: 495 (1973).

6. Chedru, J., and Cartier, P.: La perméabilité des globules rouges humains aux ions orthophosphates. Biochim. Biophys. Acta, 126: 500 (1966).

7. Chen, T. C., Castillo, L., Koricka-Dahl, M., and DeLuca, H. F.: Role of vitamin 
D metabolites in phosphate transport of rat intestine. J. Nutr., 104: 1056 (1974).

8. Condon, J. R., Nassim, J. R., and Rutter, A.: Pathogenesis of rickets and osteomalacia in familial hypophosphatemia. Arch. Dis. Childhood, 46: 269 (1971).

9. Dent, D. E.: Rickets and osteomalacia from renal tubule defects. J. Bone Joint Surg., 34B: 226 (1952).

10. Foulkes, E. C.: Effects of heavy metals on renal aspartate transport and the nature of solute movement in kidney cortex slices. Biochim. Biophys. Acta, 241: 814 (1971).

11. Fanconi, A., Fischer, J. A., and Prader, A.: Serum parathyroid hormone concentrations in hypophosphataemic vitamin D resistant rickets. Helv. Paediat. Acta, 29: 187 (1974).

12. Gerbeaux-Balsan, S.: L'absorption intestinale du phosphore dans le rachitisme vitamino-résistant hypophosphatémique héréditaire: Effets de fortes surcharges de phosphore et des régimes très pauvres en calcium. Rev. Franç. Clin. Biol., 10: 65 (1965).

13. Glorieux, F. H., and Scriver, C. R.: Loss of a parathyroid hormone-sensitive component of phosphate transport in X-linked hypophosphatemia. Science, 175: 997 (1972),

14. Glorieux, F. H., Scriver, C. R., Delvin, E., and Mohyuddin, F.: Transport and metabolism of sarcosine in hypersarcosinemic and normal phenotypes. J. Clin, Invest., 50: 2313 (1971)

15. Glorieux, F. H., Scriver, C. R., Eicher, E. M., Southard, J. L., and Travers, R.: $\mathrm{X}$-linked hypophosphatemia in Hyp/y mouse, a model of the human disease [Abstract]. Pediat. Res., 8: 899 (1974).

16. Glorieux, F. H., Scriver, C. R., Holick, M. F., and DeLuca, H. F.: X-linked hypophosphataemic rickets: Inadequate therapeutic response to 1,25-dihydroxycholecalciferol. Lancet, ii: 287 (1973).

17. Glorieux, F. H., Scriver, C. R., Reade, T. M., Goldman, H., and Roseborough, A.: Use of phosphate and vitamin D to prevent dwarfism and rickets in X-linked hypophosphatemia. N. Engl. J. Med., 287: 481 (1972).

18. Greenberg, B. G., Winters, R. W., and Graham, J. B.: The normal range of serum inorganic phosphorus and its utility as a discriminant in the diagnosis of congenital hypophosphatemia. J. Clin. Endocrinol. Metab., 20: 364 (1960).

19. Gunther, L., Cohn, E. T., and Greenberg, D. V.: Metabolism of bone salts in resistant rickets. Amer. J. Dis. Child., 66: 517 (1943).

20. Haddad, J. G., and Chyu, K. J.: Competitive protein-binding radioassay for 25-hydroxycholecalciferol. J. Clin. Endocrinol., 33: 992 (1971).

21. Harrison, H. E., and Harrison, H. C.: Intestinal transport of phosphate: Action of vitamin D, calcium and potassium. Amer. J. Physicl., 201: 1007 (1961).

22. Harrison, H. E., and Harrison, H. C.: Sodium, potassium and intestinal transport of glucose, l-tyrosine, phosphate and calcium. Amer. J. Physiol., 205: 107 (1963).

23. Hurwitz, S., and Bar, A.: Site of vitamin D action in chick intestine. Amer. J. Physiol., 222: 761 (1972).

24. Kowarski, S., and Schachter, D.: Effects of vitamin D on phosphate transport and incorporation into mucosal constituents of rat intestinal mucosa. J. Biol. Chem., 244: 211 (1969).

25. Lewy, J. E., Cabana, E., Repetto, H. A., Canterbury, J. M., and Reiss, E.: Serum parathyroid hormone in hypophosphatemic vitamin D-resistant rickets. J. Pediat., 81: 294 (1972).

26. Rosenberg, L. E.: Hereditary diseases with membrane defects. In: R. M. Dowben: Biological Membranes, pp. 255-285 (Little Brown, Boston. 1969).

27. Short, E. M., Binder, H. J., and Rosenberg, L. E.: Familial hypophosphatemic rickets: Defective transport of inorganic phosphate by intestinal inucosa. Science, 179: 700 (1973).

28. Stickler, G. B.: External calcium and phosphorus balances in vitamin D resistant rickets. J. Pediat., 63: 942 (1963)

29. Tenenhouse, H. S., and Scriver, C. R.: Orthophosphate transport in the erythrocyte of normal subjects and of patients with X-linked hypophosphatemia. J. Clin. Invest., 55: 644 (1975)

30. Vestergaard-Bogind, B.: Determination on a micro scale of concentration and specific radioactivity of inorganic phosphate ions in whole blood and packed red cells. Scand. J. Clin. Lab. Invest., 157: 457 (1964).

31. Wasserman, R. H., and Taylor, A. N.: Intestinal absorption of phosphate in the chick: Effect of vitamin $\mathrm{D}_{3}$ and other parameters. J. Nutr., 103: 586 (1973).

32. Kindly given to us by Dr. Claude Arnaud.

33. We are grateful to Mireille Dussault for the technical assistance, and to Jeannine Mikan for assistance with the manuscript.

34. Dr. F. H. Glorieux is a Scientist of the Queen Elizabeth II Canadian Research Fund to aid in research on the diseases of children.

35. This research was supported by the Shriners of North America, Grant M3320 of the Medical Research Council of Canada, Grant 720143 of the Conseil de la recherche en Santé du Québec, and la Fondation Lacoste-Beaubien.

36. Requests for reprints should be addressed to: F. H. Glorieux, M.D., Ph.D., The Genetics Unit, Shriners Hospital for Crippled Children, 1529 Cedar Ave., Montreal H3G 1 A6 (Canada).

37. Accepted for publication January 14, 1976.

\title{
The Transplacental Migration and Accumulation in Blood of Volatile Organic Constituents
}

\author{
B. J. DOWTY AND J. L. LASETER ${ }^{129}$ \\ University of New Orleans, Department of Biological Sciences, New Orleans, Louisiana, USA \\ J. STORER
}

Charity Hospital of Louisiana at New Orleans, New Orleans, Louisiana, USA

Extract

Gas chromatographic-mass spectrometric analysis of profiles of low molecular weight volatile organic constituents obtained from cord blood and maternal blood samples collected at birth reflect transplacentally acquired compounds. The transplacental passage of halogenated hydrocarbons, plastic components, and abnormal accumulations of compounds have been demonstrated. In the 11 paired cord blood-maternal blood samples analyzed, the relative amounts of constituents in cord blood closely correspond to those quantities present in the maternal blood. However, some of the over 100 components are present in the cord blood in significantly higher concentrations than in the maternal blood, suggesting a possible selective one-way transfer of certain constituents into the fetus. Benzene, carbon tetrachloride, and chloroform are present in quantities equal to or greater than in maternal blood. In one infant with a lumbosacral meningomyelocele abnormally high concentrations of acetone, other components, and the food preservative 2,6-di-tert-butyl-4-methylphenol (BHT) were identified. 